\title{
Ciprofloxacin in Elderly Patients with Pneumonia
}

\author{
Tanveer Mir, M.D., Alaa Soltan, M.D., Javed Mir, M.D. \\ Riyad Basir, M.D., Faroque Khan, M.D., F.C.C.P. \\ East Meadow, New York
}

DOI: http://dx.doi.org/10.5915/24-1-15451

\begin{abstract}
From January 1987 to July 1989, we prospectively evaluated the safety and efficacy of a fluoroquinolone, ciprofloxacin (Cipro), in the treatment of elderly patients hospitalized with pneumonia. Of the 39 patients, there were 25 females and 14 males, with an age range of 65-94 years (mean age 79.1 years). The four common pathogens were Pseudomonas aeruginosa (12), Streptococcus pneumoniae (5), Haemophilus parainfluenza (5), Staphylococcus aureus (5). All isolates were sensitive in vitro. Ciprofloxacin was given intravenously (IV) $200 \mathrm{mg}$ every 12 hours. When the patient was able to take oral medication, therapy was switched to oral ciprofloxacin $500 \mathrm{mg}$ every 12 hours. Mean duration of IV/PO therapy was 5.8 days.

\begin{tabular}{c|c|c|c|c|c|c}
\hline & $\begin{array}{c}\text { Culture } \\
\text { Positive }\end{array}$ & $I^{*}$ & GNB $^{*}$ & GPC $^{* * *}$ & $\begin{array}{c}\text { Success/ } \\
\text { Failure }\end{array}$ & Indent $^{\text {Ino 39 }}$ \\
\hline
\end{tabular}

*Isolates **Gram (-) Bacteria ***Gram (+) Cocci

This sudy concluded: 1) In the elderly, ciprofloxacin is useful due to convenience of BID dosage, sequential IVIPO availability, good safety and efficacy. 2) Ciprofloxacin shows good in vitro activity. 3) Clinical results are comparable to the results obtained with conventional antimicrobial therapy for treatment of pneumonia in the elderly. 4) All 5/39 ciprofloxain-treated patients with $S$. pneumoniae as an isolate were cured. 5) Quinolones are cost effective. Early use of oral Cipro in the 39 patients resulted in estimated savings of approximately $\$ 6,000$.
\end{abstract}

Key words: Ciprofloxacin, pneumonia, elderly.

The elderly, defined as individuals over the age of 65 years, currently comprise 11 percent of the

From the Department of Medicine

Nassau County Medical Center

East Meadow, NY

Presented at the IMA 24th Annual Convention Long Island, New York, July 1991

Reprint Requests: Tanveer Mir, M.D.

Department of Medicine

Nassau County Medical Center

2201 Hempstead Turnpike

East Meadow, NY 11554 population. It is estimated that by the year 2030 , this number will likely increase to $17 \% .^{1}$ Respiratory infections are the fourth leading cause of death in the elderly, exceeded only by atherosclerosis, chronic obstructive pulmonary disease and cirrhosis of the liver. The greatly increased mortality of respiratory infections in the elderly has been ascribed to agerelated impairment in host defenses, ${ }^{2-4}$ existing comorbid conditions like diabetes and atherosclerosis, increased oropharyngeal colonization with Gramnegative bacillis and, finally, atypical presentations causing a delay in diagnosis.

Elderly patients undergo gradual physiological changes which influence absorption, distribution and elimination of certain drugs. Decreased lean body mass, total body water and albumin, as well as in- 
creased body fat result in altered distribution of both lipophilic and hydrophilic agents. ${ }^{6,7}$ In addition, hepatic and renal mechanisms of drug elimination gradually become less effective with advancing age. ${ }^{6,7}$ While many new antimicrobial agents continue to be introduced for lower respiratory tract infections, their narrow margin of safety and limited spectrum of activity limit their use in the elderly.

When the sulfonamides first appeared in the 1930s, antimicrobial chemotherapy became a new clinical science. The sulfonamides seemed to represent an astounding therapeutic advance, but equally amazing improvements have appeared every decade since then. In the 1940s, the miracle was penicillin G; in the 1950 s, erythromycin, the tetracyclines, and chloramphenicol were the miracle drugs.

In the 1960s came ampicillin and methicillin, soon joined by the aminoglycosides and cephalosporins; thus, it became easier but infinitely more complex to care for patients with bacterial infections. Up to that time, practically any interested clinician could become an expert in managing infectious diseases. However, the need for specialists' help in this area became obvious to all in the 1960 s.

In the 1970s, new penicillins and new cephalosporins began to appear regularly. In the 1980 s, we saw improved cephalosporins and, more important, the newer fluoroquinolones, which are unique and represent an exciting development of the entire progression of antibiotics.

The fluoroquinolones are active against the majority of aerobic Gram-positive and Gram-negative bacteria seen in clinical practice which are otherwise resistant to oral agents, i.e. Pseudomonas aeruqinosa. Clinical studies have shown that quinolones are effective in the treatment of infections of urinary tract, lower respiratory tract, skin and skin structures, bones and joints and gastrointestinal tract. Many of these infections that are treated successfully by ciprofloxacin are caused by pathogens that are resistant to other oral and parenteral antimicrobial agents. ${ }^{9}$

The data for this study was derived from a study conducted from January 1987 to June 1989 at Nassau County Medical Center, a 615-bed teriary care public hospital located in the suburbs of New York City. A total of 39 patients were considered evaluable for the study. One hundred forty patients were evaluated in a prospective clinical trial $^{1}$ comparing sequential intravenous-oral administration of ciprofloxacin to intravenous ceftazidime in serious bacterial pneumonias. Of the 144 patients evaluated in this study 39 patients were over 65 years of age and enrolled in our study. ${ }^{2}$

\section{Patients and methods}

Patients hospitalized at Nassau County Medical Center between January of 1988 and July 1989 for community-acquired, hospital-acquired, or nursing home-acquired bacterial pneumonia were enrolled in the study. All enrolled patients were over 65 years of age, range 65-94 years (mean age 79.1 years). Bacterial lower respiratory tract infection was diagnosed if patients had compatible clinical picture, i.e., fever over $37.2^{\circ} \mathrm{C}$, total white blood cell count over $10,000 / \mathrm{cu} \mathrm{mm}$, and productive cough with purulent sputum, or a positive sputum culture from a specimen which, on Gram stain, had less than 25 squamous epithelial cells, and $\mathbf{2 5}$ or more neutrophils per low-power field. Patients were excluded if they were under 65 years of age, serum creatinine value was more than $2 \mathrm{mg} / \mathrm{dl}$, allergic to quinolones, or if their condition was hemodynamically unstable.

\section{Antibiotic administraction}

Patients received sequential ciprofloxacin IV 200 $\mathrm{mg} Q 12$ hours (mean 4.1 days), followed by $500 \mathrm{mg}$ PO Q 12 hours (mean 5.8 days). Thirty-nine patients were enrolled in this group. Written, informed consent was granted by the patient or his/her legal guardian prior to enrollment.

Response definitions at the end of treatment were determined using the following definitions:

1) Complete resolution: disappearance of all signs and symptoms related to the infection.

2) Improvement: marked to moderate reduction in the severity and/or number of signs and symptoms of infection.

3) Failure: insufficient lessening of the signs and symptoms of infeciton to qualify as improvement.

Bacteriologic response was determined using the following definitions:

1) Eradication: causative organism(2) absent at the end of treatment.

2) Persistence: causative organism present at the end of treatment judged to be causing a new infections process.

3) Indeterminate: bacteriologic response to study medication not evaluable for any reason, e.g., another anti-microbial with a similar spectrum of activity was administered before obtaining samples for the post-treatment cultures.

\section{Clinical Monitoring}

In addition to a baseline thorough history and physical, laboratory tests, including complete blood cell count and serum chemistry were performed before and after therapy. Pre-enrollment and followup chest roentgenography was performed in all patients. All patients were monitored daily for any adverse reactions in addition to daily documentation of physical examination, fever, cough and sputum production.

Antibiotic therapy was evaluated using the following definitions: 
Table 1. Patient charcteristics on enrollment.

\begin{tabular}{ll}
\multicolumn{1}{c|}{ Characteristic } & \multicolumn{1}{c}{ n } \\
\hline Number in study & 39 \\
Mean age (Yrs) & 79.1 \\
Male & 14 \\
Female & 25
\end{tabular}

\begin{tabular}{|c|c|}
\hline Severity of infection & $\mathbf{n}$ \\
\hline Severe & 17 \\
\hline Moderate & 21 \\
\hline Mild & 1 \\
\hline Underlying diseases & $\mathbf{n}$ \\
\hline Atherosclerosis & 17 \\
\hline Organic brain syndrome & 7 \\
\hline Underlying malignancy & 4 \\
\hline Hypertension & 8 \\
\hline Diabetes mellitus & 5 \\
\hline Seizure/cerebro vascular accident & 8 \\
\hline Gastrointestinal bleed & 4 \\
\hline Chronic obst. pulm. dis. & 21 \\
\hline None & 1 \\
\hline 3 or more than 3 & 32 \\
\hline Sputum culture characteristic & $\mathbf{n}$ \\
\hline Polymicrobal & 15 \\
\hline Single pathogen & 12 \\
\hline Culture nagative & 10 \\
\hline Unidentified & 2 \\
\hline Sputum culture characteristic & $\mathbf{n}$ \\
\hline Gram-negative bacteria & 42 \\
\hline Gram-positive cocci & 12 \\
\hline
\end{tabular}

\begin{tabular}{l|l}
\hline \multicolumn{2}{c}{ Blood culture characteristics } \\
\hline Organism & $\mathrm{n}$ \\
\hline Streptococcus faecalis & 1 \\
\hline
\end{tabular}

1) Clinical cure: Defined as disappearance of previously documented signs and symptoms of infection.

2) Clinical failure: Defined as the continuation or worsening of signs and symptoms of infection.

3) Bacteriologic eradication: Defined as elimination of pretreatment pathogens from sputum.

4) Bacteriologic failure: Defined as persistence of the original pathogen and/or isolation of a new pathogen on post-treatment sputum cultures.

\section{Results}

During an 18-month period, between January 1988 and July 1989, 39 cases of pneumonia in patients over 65 years of age admitted to Nassau County Medical Center were evaluated.

Infection was classified as mild, moderate, or severe based on physical examination and radiographic signs.
Table 2. Organisms identified in 29 isolates present as single isolates or mixed flora.

\begin{tabular}{lr}
\multicolumn{1}{c}{ Organism } & n \\
\hline Pseudomonas aeruginosa & 12 \\
Streptococcus pneumoniae & 5 \\
Staphylococcus aureus & 5 \\
Hemophilus parainfluenzae & 5 \\
Enterobacter aerogenes & 4 \\
Group B Streptococcus & 2 \\
Klebsiella pneumoniae & 3 \\
Hemophilus influenzae & 2 \\
Pseudomonas maltophila & 3 \\
Proteus mirabilis & 2 \\
Enterobacter cloacae & 2 \\
Citrobacter diversus & 2 \\
Unidentified & 2 \\
Serratia marcesens & 1 \\
Moraxella (Branhamella) catarrhalis & 0 \\
Acinetobacter anitratus & 0 \\
Escherichia coli & 1 \\
Streptococcus faecalis & 1 \\
Providencia stuartii & 1 \\
\hline
\end{tabular}

Sputum specimens were obtained in $95 \%$ of the patients. Gram stain or culture yielded potential pathogens in 29 of 39 cases. The four most common pathogens were Pseudomonas aeruginosa (12), Streptococcus pneumonae (5), Haemophilus para (5), Staphylococcus aureus (5). All of the bacterial isolates cultured were sensitive to ciprofloxacin in vitro. Only one patient out of $39(2.5 \%)$ had bacteremia due to Streptococcus faecalis. These results are significantly different from Paterson et al $^{13}$ where $5.8 \%$ of the study group had bacteremia.

Cure was seen in $71 \%$ of patients, regardless of severity of illness and existence of other comorbid conditions. Antibiotic failure was noted in one patient. One patient showed clinical deterioration and was changed to other antibiotics. Sputum showed Enterobacter aerogenes and Pseudomonas aeruginosa.

Adverse drug reaction was noted in only one patient. One patient in the ciprofloxacin group developed rash, fever while receiving IV ciprofloxacin, and this was discontinued.

In terms of mean number of days requiring hospitalization, IV ciprofloxacin was given for a mean of 4.1 days. Nonetheless, a majority of the patients could be discharged early in each group and followed up with oral ciprofloxacin.

\section{Discussion}

The proportion of patients in the United States who are over 65 years of age has increased from $4 \%$ to $12 \%$ in the last 80 years. The $12 \%$ of Americans over 65 years of age accounts for $40 \%$ of days in hospital, $25 \%$ of all medications used, and $33 \%$ of 
Table 3. Treatment outcome.

\begin{tabular}{l|c|c|c}
\hline \multicolumn{1}{c}{ Outcome } & Ciprofloxacin & Ofloxacin & \multicolumn{1}{c}{ Total } \\
\hline Number in study & 39 & 30 & 69 \\
Cure & 28 & 20 & $48(69.6 \%)$ \\
Indeterminate & 5 & 2 & $7(10.1 \%)$ \\
Failure & 1 & 4 & $5(7.2 \%)$ \\
Deaths & 5 & 4 & $9(13.04 \%)$ \\
\hline
\end{tabular}

Table 4. Characteristics of Patients who died.

\begin{tabular}{|c|c|c|c|c|c|c|c|}
\hline $\begin{array}{l}\text { Patient } \\
\text { number }\end{array}$ & $\begin{array}{c}\text { Age/ } \\
\text { sex }\end{array}$ & Diagnosis & Underlying disease & $\begin{array}{l}\text { Severity of } \\
\text { infection }\end{array}$ & $\begin{array}{l}\text { Infecting } \\
\text { organism }\end{array}$ & Antibiotic & Comment \\
\hline 1) $\mathrm{BW}$ & $78 / \mathrm{F}$ & Pneumonia & $\begin{array}{l}\text { End-stage COPD* } \\
\text { ASHD*, cerebral } \\
\text { athersclerosis, } \\
\text { peptic ulcer disease, } \\
\text { osteoporosis }\end{array}$ & Severe & $\begin{array}{l}\text { E. coli } \\
\text { Klebsiella } \\
\text { pn. }\end{array}$ & $\begin{array}{l}\text { Cipro I/V } \\
21 / 2 \text { days }\end{array}$ & $\begin{array}{l}\text { Severe gas } \\
\text { exchange } \\
\text { problems; } \\
\text { DNR* }\end{array}$ \\
\hline 2) $\mathrm{JL}$ & $68 / F$ & Pneumonia & None & Moderate & $\begin{array}{l}\text { Pseud. } \\
\text { aerugin. } \\
\text { H. parainfl. } \\
\text { Strep } \\
\text { faecalis- } \\
\text { Blood }\end{array}$ & $\begin{array}{l}\text { Cipro } \mathrm{I} / \mathrm{V} \\
\times 4 \mathrm{PO} \times \\
15 \text { days }\end{array}$ & Sputum (-) \\
\hline 3) $\mathrm{RMM}$ & $78 / \mathrm{M}$ & Pneumonia & $\begin{array}{l}\text { Long-standing } \\
\text { COPD*, } \\
\text { hypertension, } \\
\text { rheumatoid arthritis }\end{array}$ & Moderate & H. parainfl. & $\begin{array}{l}\text { Cipro } 200 \mathrm{mg} \\
\mathrm{I} / \mathrm{V} \times 2 \\
11 / 2 \text { days }\end{array}$ & $\begin{array}{l}\text { Protocol } \\
\text { discontinue on } \\
\text { family request }\end{array}$ \\
\hline 4) $\mathrm{BF}$ & $81 / \mathrm{M}$ & Pneumonia & None & Moderate & H. parainfl. & $\begin{array}{l}\text { Cipro } 200 \mathrm{mg} \\
\text { IV } \times 3500 \\
\mathrm{mg} \text { PO twice } \\
\text { daily } \times 8\end{array}$ & \\
\hline 5) $\mathrm{LR}$ & $80 / \mathrm{F}$ & Pneu/UTI & $\begin{array}{l}\text { Hypertension, } \\
\text { COPD*, seizure } \\
\text { disorder, organic } \\
\text { brain synd. }\end{array}$ & Severe & $\begin{array}{l}\text { Citrobacter } \\
\text { diversus }\end{array}$ & $\begin{array}{l}\text { Cipro } 200 \mathrm{mg} \\
\text { IV } \times 2 \times 5 \\
\text { days; } 500 \mathrm{mg} \\
\mathrm{PO} \times 2 \times 3 \\
\text { days }\end{array}$ & $\begin{array}{l}\text { Bact. and } \\
\text { clinical } \\
\text { impression. } \\
\text { Tracheal } \\
\text { aspira (-). } \\
\text { Pneumonia } \\
\text { improved. }\end{array}$ \\
\hline
\end{tabular}

*COPD - Chronic Obstructive Pulmonary Disease

*ASHD - Arteriosclerotic Heart Disease

*DNR - Do Not Resuscitate

*OBS - Organic Brain Syndrome

* $\mathrm{CHF}$ - Congestive Heart Failure

*CVA - Cerebrovascular Accident

health-care expenses. The number of elderly persons is expected to be 51 million by 2020 . Respiratory infections are the fourth leading cause of death in the elderly." New antimicrobials have been limited by their narrow margin of safety and limited spectrum of activity for their use in the elderly. In contrast, the newer quinolones, offer a number of advantages. From our experience with the use of the fluoroquinolones - ciprofloxacin and ofloxacin in the elderly, we conclude that:

a) In the elderly, quinolones are useful due to conve- nience of twice daily (b.i.d.) dosing, sequential IV/PO availability, good safety and efficacy.

b) Ciprofloxacin shows excellent in vitro activity.

c) Clinical results are comparable with conventional parenteral therapy. ${ }^{11}$

d) All 5 patients with S. pneumonia identified in sputum were cured, having a cure rate of $100 \%$.

e) Fluoroquinolones can shorten the hospital stay in elderly patients due to availability of oral therapy; early use of oral ciprofloxacin alone in 39 patients resulted in estimated savings of approximately 


\section{$\$ 6,000$. $^{1}$}

f) Of the 39 patients evaluated, five patients died in the hospital. This mortality figure of $13 \%$ is low as compared to a mortality figure of $40 \%$ in other studies. ${ }^{12}$ The mean age of our patients was 79.1 years, and they had multiple medical problems that are associated with an increased risk of death. ${ }^{13}$ The low incidence of bacteremia, 2.5\% may be related to a lower mortality rate, as pointed out in several studies. In the Marrie et al. study, ${ }^{14} 4 \%$ incidence of bacteremia was related to $40.5 \%$ mortality.

The presenting signs and symptoms in our patients, are similar to those represented by other investigtors. ${ }^{\text {"S }}$ Sputum Gram stains and cultures are helpful in guiding therapy; obtaining adequate samples in the debilitated population is not easy. The isolation of Gram-negative bacteria, on sputum culture, corroborates with current literature. However, Staph. aureus, which is an uncommon isolate in sputum, was present in five patients. Streptococcus pneumonia isolated in five patients showed $100 \%$ cure rate. These findings are in keeping with the literature, where ciprofloxacin showed MIC's in the range of $.85-3.4 \mathrm{~g} / \mathrm{ml}$, but resulted in $100 \%$ eradication. ${ }^{15-17}$ An explnation for this relates to the fact that ciprofloxacin has a high volume of distribution, suggestion that the drug's concentration in tissues can well exceed serum levels for prolonged periods of time. ${ }^{19,20}$ Bergogne et al. in a study of 21 patients, showed the ratio of serum to bronchial levels was .19 $\mathrm{mg} / \mathrm{ml}$ at two hours and $.95 \mathrm{mg} / \mathrm{ml}$ at six hours. ${ }^{20}$ We believe that this unique pharmacokinetic feature of ciprofloxacin, whereby high concentrations of the drug are achieved and maintained in the bronchial and pulmonary parenchymal tissue, overcomes the marginal in vitro susceptibility against $\mathrm{S}$. pneumoniae and helps explain the very high cure rate in this type of infection.

The patients enrolled in our study had multiple comorbid medical conditions. Out of 39 patients, three patients had tracheostomies. Ciprofloxacin is a suitable alternative to conventional antibiotics due to broad spectrum and availability of sequential intravenous and oral forms, which can result in reduced length of hospital stay. The concurrent presence of UTI and skin and bone infections, which are not uncommon in this age group, clearly make even long-term use of quinolones easy and cost effective. Ciprofloxacin has been shown to be safe and effective in the treatment of lower respiratory tract infections, particularly those caused by Gram-negative bacilli, including $\mathrm{H}$. influenzae, Moraxella (Branchamella) catarrhalls Enterobacteriacae and P. aeruginosa. ${ }^{21}$ Ciprofloxacin was effective in the treatment of pneumonia in the elderly, and the results were comparable to conventional parenteral antibiotic therapy. The drug was well tolerated and was cost effective. Thus, the fluoroquinolones represent an important new addition to the broad class of antimicrobials.

\section{References}

1. Khan FA, Basir R: Sequential intravenous-oral administration of ciprofloxacin vs. ceftazidime in serious bacterial respiratory tract infecions. 1989;96:528-37.

2. Soltan A, Mir J, Khan FA: Sequential intravenous-oral administration of ofloxacin vs. ceftazidime in serious bacterial respiratory tract infections. Absttract 3-International Symposium on Quinolons: Vancouver, Canada. July 12-14, 1990.

3. Gleckman RA, Esposito AL: Fever of unknown origin in the elderly: diagnosis and treatment. 1986;41:45-7, 50-2.

4. Verghese A, Berk SL: Bacterial pneumonia in the elderly. Medicine 1983;62:271-85.

5. Yashikama TT: Aging and infectious disease. State of the art gerontology 1984;30:275-78.

6. Greenblatt DJ, Sellers EM, Shader RI: Drug disposition in gold age. $\mathrm{N}$ Engl $\mathrm{J} \mathrm{Med}$ 1982;18:1081-88.

7. Schmucker DL: Aging and drug disposition: an update. Pharmacol Rev. 1985;36:133-48.

8. Clark RJ: Overview of fluoroquinolones in respiratory tract infection. J Repiratory Diseases. Suppl. May 1990;11(5):S6-S12.

9. Sanders WE Jr.: Efficacy, safety and potential economic benefits of oral ciprofloxacin in the treatment of infections. Rev. Infect. Dis. 1988; 10:528-43.

10. Finkelstein MS: Unusual features of infection in the aging. Geriatrics 1982;32:65-78.

11. Valenti W, Trudell G, Bentley DW: Factors predisposing to oropharyngeal colonization with Gram-negative bacilli in the aged. N Engl J Med 1978;298:1109-11.

12. Garibaldi RA, Nurse BA: Infections in the elderly. Am J Med 1986;81:53-8.

13. Paterson PK, Stein D, David RP, Guay D, Logan G, Obaid S, Grunninger R, Davies S, Breitenleucher R: Prospective study of lower respiratory tract infections in an extended case nursing home program: potential role of oral ciprofloxacin. Am J Med 1988;85-1:164-171.

14. Marrie TJ, Durant M, Kwan C: Nursing homeacquired pneumonia. A case control study. J Am Geriatric Society 1986;146:2353-2357.

15. Mufson MA: Pneumococcal infections. JAMA 1981;246:1942-45.

16. Marrie TJ, Haldane EV, Faulkner RS, Durant M, Kwan C: Community-acquired pneumonia requiring hospitalization: Is it different in the 
elderly?. J Am Geriatric Soc 1985;33:671-80.

17. Gleadhill K, Ferguson WP, Lowry RC: Efficacy and safety of ciprofloxacin in patients with respiratory tract infections in comparison with amoxacillin. J Antimicrobial Chemother 1986;18(Suppl. D)133-38.

18. Raoof S, Wollschlager CM, Khan F: Treatment of respiratory tract infections with ciprofloxacin. J Antimicrob Chemother 1986;18(Suppl D):139-45.
19. Khan FA: Ciprofloxacin in the treatment of lower respiratory tract infection due to streptococcus pneumoniae. Int Med 1989;10:33-8.

20. Bergogne-Berezin E., Berthelot G, Even P, Stern M, Reynaud P: Penetration of ciprofloxacin into bronchial secretions. Eur J. Clin Microbial 1986;5:197-200.

21. Fass, RJ: Ciprofloxacin, best use of this new broad spectrum antibiotic. Postgraduate medicine 1990;87(8). 